\title{
An Interoperability Framework for E-Government Heterogeneous Information Systems
}

\author{
Hillan Ronoh ${ }^{1}$, Kelvin Omieno ${ }^{2}$, Stephen Mutua ${ }^{3}$ \\ Department of Information Technology, Masinde Muliro University of Science and Technology, \\ Kakamega, 50100, Kenya ${ }^{1}$ \\ Department of Computer Science, Masinde Muliro University of Science and Technology, Kakamega, 50100, Kenya ${ }^{2}$ \\ Department of Information Technology, Meru University of Science and Technology3
}

\begin{abstract}
Information Communication and Technology (ICT) utilization has become a backbone of e-government implementation. Six components of information system (hardware, software, people, data, process and network) are combined to deliver information from government to their citizen as part of public services. However, there is an interoperability challenge on e-government implementation related to information system. Organizations in Kenya have automated processes and digitize services and information using various information systems e.g. IFMIS systems which acts as a financial management of government departments. These systems due to different vendors and their use of different storage types, data formats, languages and middleware platform have become diverse, thus the issue of egovernment information system heterogeneity and interoperability. This has led to the need for organizations to share information and services through interoperability platforms. Currently most e-government platforms are independent thus result to lack of integration, inconsistency of meaningful data, redundancy of effort and lack of integration. The main aim of this Study was to develop an interoperability framework for e-government information system which will improve efficiency and effectiveness of government services through accurate information among various information systems while the specific objectives were to identify the factors that affected e-government information system interoperability, determine the critical factors that influenced e-government information system interoperability. The Research design used was exploratory study of both national and county governments in Kenya. It focused on the way public organizations managed identity-related data and the sharing of such data, either with other public agencies or with private organizations. The study adopted a mixed methods approach where both quantitative and qualitative data was used. Quantitative data was analyzed descriptively based on the information from the questionnaire and based on the research questions. Factor analysis was conducted on the two sets of data. The target population was users of egovernment information systems in county government and government ministries in Kenya. The study sample was drawn from two county governments and two huduma centres in Kenya. Descriptive statistical analysis and principal component analysis was used. The findings of this study will be essential to both the government and county governments in improving efficiency and effectiveness of government services and also form a basis for future development of interoperability of e-government information systems. The framework was successfully accepted by the experts who were interviewed by the researcher. The framework recombines interoperability framework of egovernment in guiding decision makers to better manage issues related to e-government information system interoperability.
\end{abstract}

Keywords: Information system, Heterogeneity, Interoperability, e-Government information systems, IFMIS

\section{INTRODUCTION}

Electronic government (e-Government) has various definition based on different authors. Gil-Garcia and Pardo (2005) defined it as the intensive usage of information technologies for providing public services which may lead to improvement of, promotion of democratic values working mechanisms and eventually leads to managerial efficiency. Another author [1] defined e-Government as the utilization of the information technology, with the help of the internet as a medium, to improve services offered by government which helps in service delivery to citizens, businesses, and other government agencies. The advancements and use of ICT to eventually provide the general public sector with egovernment services to citizen and business entities. That means recent and advanced technology usage such as mobile technology and using the mediums such as the internet has led to eventually improved better government services[2]. 
The Kenyan government mainly focuses on four types of interactions between government and its stakeholders based on e-government. These interaction types are; Government-to-Citizen (G2C) which focuses on delivering e-services from government entities to citizens such as taxes/billing, licenses renewing, and payment of government projects/contracts etc. Government-to-Business (G2B) deals with electronic transfer of public services between the governments to businesses. These services include e-procurement, importing/exporting goods services and customs. Government-to-Government (G2G) involves communication via available secure government network (SGN) of data and information within Governmental entities and within government internal entities example of the system is the IFMIS which is popularly used. Government-to-Employee (G2E) involves sharing of data and information through transactions of government to its employee by use of governmental Management information systems example of this system used is the Government Human Resources Information Systems (GHRIS).

Therefore there is need for Government and its stakeholders to connect internally and externally (i.e. G2C, G2B, G2G and G2E) to achieve e-Government aims. The key concept to ensure that e-government systems share meaningful data and information consistency without data redundancy is by use of interoperability [3]. According to [4], the ability of different types of Information and Communications Technology (ICT) systems to work together in order to exchange data and information efficiently in a meaningful and useful manner is known as interoperability. To achieve services being delivered to citizens, business and government itself government need to share data accurately and meaningful for a project to be achieved [5]. In order to achieve this, the government in Kenya needs to put their efforts on improvements in various areas such as ICT infrastructure, common services based on standards and policies, have multiple secured channels and one stop service delivery to enhance service delivery in an effective and efficient manner. Furthermore, transparency, cost reduction, easy access to government services and transparency should be the main focus of any government to build the confidence and satisfaction of government customers, both citizens and business. Moreover for interoperability to be achieved amongst various information systems between the eGovernment agencies there are key factors that need to addressed such as performance, standardization, flexibility, availability, reliability, response time and integration [6].

The interoperability of e-Government information systems become successful when some parameters are put into consideration this factors are: Top management support with clear strategy, ICT infrastructure, Policies amongst different departments in government, ICT literacy levels to use the information systems, security and privacy this will eventually build trust to use the services delivered. This parameter work hand in hand for government to implement successful projects and deliver services without meeting any of the parameters it will act as an obstacle [7]. For this it is important to study how interoperability of information systems can be achieved amongst different government agencies and investigate how information systems interoperability enhances the delivering of services to customers. It is also vital to identify the key issues that hinder successful IS interoperability implementation to be achieved.

The end of the first decade of the 21 st Century has been described as both an historical turning point in the development of e-Government systems. Various governments have seen the launch of various systems aimed at improving the delivery of services and sharing of government information more accessible. The aim being to help public authorities use ICT to offer better services at lower cost, while making life easier and better for citizens and businesses. There is need to empower citizens and businesses to improve mobility by having a single user centric information system which will enable efficiency and effectiveness [8].

The Kenyan government is moving towards having a centralized user-centric information system for operations to become more efficient operationally and also this will led to collaboration across traditional departments. The government should have an efficient and elaborate information system where data and information can be shared effectively. The government is not only meant to bring services to the public. By reducing overall operational costs and transforming the e-Government into organizations that meets the public needs will eventually led to improved economic and social values [9]. This involves implementation of various information systems such as management support systems, operations support systems, transaction processing systems, human resources management system, electronic messaging and collaboration system, IMIS (Integrated multicultural information system), IFMIS, EMIS (Environmental management information system), Transport management system, Ledger management System and National electronic single window system for various staff distributed across different government offices in different ministries and autonomous bodies [9].

In 2004 the Kenyan government set up a body to be an oversight body of all ICT projects within the government. The body was known as the Kenya E-Government Secretariat which primary mandate was to oversee government ICT projects to enhance service delivery of all government ministries [9]. Ever since a lot of electronic systems have been implemented in various government departments and other state-owned institutions, including the integrated financial management systems, educational systems and software's, K.R.A which is the national tax systems, immigration information system and legal information system amongst other information systems. These e-government information systems which are deployed across various government ministries and department do exchange information and data manually using emails, fax and electronic media such as flash disks. This often results in data duplication, loss of data integrity, different data formats and thus unnecessary excessive expenditure. Therefore, establishing the idea of a common interoperable information infrastructure is the key to the success of implementation of various e-governments 
heterogeneous information system. E-governance plays a crucial role in providing anytime or everywhere services to the citizens. This is achieved through the development and implementation of various information systems aimed at automating various government services. However, the heterogeneity of these systems leads to diverse program languages, data formats, heterogeneous data storage methods and vendor's system access between closed and open systems amongst the levels of government. As a result this it has led to lack of shared information, duplication of effort, data redundancy, data inconsistencies and long inter-departmental information verification inefficiencies. To overcome these challenges and reinforce the goals and benefits of e-governance heterogeneous information systems, interoperability remains key to deployment of new ICT systems. $85 \%$ of the government budget would be saved if government initiatives were to be implemented focusing on addressing interoperability [10]. This paper presents an interoperability framework for e-government heterogeneous systems that allows seamless flow of data within departments at any level of government.

\section{RELATED LITERATURE}

Interoperability is vital for government agencies to improve government operations and provide services to citizens by use of the e-government information systems [11]. Some of the key parameter to be addressed for interoperability to be addressed are the development of new service integration capability, creation of new connectivity among networks and emergence of new technologies [12]. As a facilitator of transformation and innovation by government it is necessary to have a seamless flow of information and data [13]. For connected government to be achieved there need to be interoperability of information system which will led to system integration, cross-boundary collaboration therefore leads to information sharing [12].

The primary goals associated with achieving interoperability amongst heterogeneous information systems are data exchange, meaning exchange and process agreement [14].

a) Data exchange is a goal of interoperability whether the data is exchanged manually or electronically. Exchange can be from different mediums from emails, phone connections and document exchanges via web pages. Lack of interoperability has an impact on service delivery amongst major stakeholders in government. Collaborative, efficient government and effective delivery of seamless services is a key factor of interoperability [15]. Architectural interoperability is a key factor towards a more advanced e-government information system [16]. Standard and policies which is a key element to achieve interoperability hinders government-to-government (G2G) development efforts.

b) The second goal is exchange of meaning which generally means assigning the same meaning to either data or information being exchanged. This is a key factor to avoid misinterpretation of data. This goal is difficult to achieve because there will be no guarantee that all the participants will successfully interpret the meaning data in the same way [14]. The gain of interoperability of information systems is for transparency, collaboration and participation to occur with the help of e-government [17].

c) Finally the third goal is agreement on how to deal with the information that has already been exchanged. Process agreement is a key goal of interoperability which focuses from the information exchanged to the actions taken when the information exchange has already occurred [14].There should be agreement of the various agencies on what to do with the data they have already received. Process agreement is vital because a consumer can provide the same information to different government services in response to a single citizen centric event.

\subsection{Types of e-government interoperability in Information Systems}

\subsubsection{Technical Interoperability}

This is considered as the key element for a government or organization to achieve interoperability. Technical interoperability has the following domains data schema, data accessibility, Data common standards, ICT infrastructure such as hardware, networking and communication, security and privacy and emerging application and technology. These domains are addressed in the study individually and act as a building block of technical interoperability [18]. Exchanging data in an agreed format of messages via communication protocols and platforms should be clear within various government agencies [19].

Basically technical interoperability revolves around linking of computer elements and services It basically involves interconnection of services with open interfaces, data presentation and meaningful exchange of the data, data integration and middleware security aspects and accessibility of the services to all [20].

\subsubsection{Semantic Interoperability}

The semantic interoperability dimension is concerned with ensuring that the precise meaning of exchanged information among computer systems and services is understandable, even though they were not initially developed with the purpose to interoperate. Semantic interoperability enables systems to combine received information with other information resources and to process it in a meaningful manner[20]. 
It maps around meaningful exchange and it is normally placed above the technical interoperability level. This is because in order to exchange meaningful data and information there should have already been success in information exchange. Many of the existing models conform to the same attribute. This is whereby the data received from different government agencies are stored into internal databases and processed to output meaningful information [18]. Specifying common data definitions and developing knowledge based management systems and information models based on semantic interoperability. Transmission phase should put into consideration agreements and information types before developing anay information system [19].

\subsubsection{Organizational Interoperability}

It aims to link processes among different organizations. Conventional, organizational architecture consists of the formal organization, informal organization, business processes, strategy and human resources [21]. These components can be understood as the building blocks that are mandatory for designing an organizational interoperability. To obtain organizational interoperability in e-governance, agencies with different work practices must be able to design a common stage where this work takes place.

To achieve organizational interoperability in information systems it requires collaborations between government agencies. To achieve economic and social benefits organizations should align their information architectures to make it available of all the services it offers accessible to citizens [18]. Data received from different entities should be combined with information systems to deliver accurate and meaningful data to the public this will led organization to meet their organizations goals and in turn enhance productivity. New services being introduced or adopted should be agreed upon by all stakeholders [19].

\subsection{Interoperability of HIS (Heterogeneous Information System)}

There is unanimous agreement that high quality and comfortable online delivery of governmental services often requires the seamless exchange of data between two or more government agencies. Smooth data exchange, in turn, requires interoperability of the databases and workflows in the agencies involved [22].

The ability of multiple and diverse government organizations to exchange meaningful data and in turn integrate information across different organization boundaries is key determinant of successful government initiatives [23]. Interoperability is believed to ensure effective service to citizens and to perform governmental functions effectively as well as efficiently [24]

Integration of e-government enterprises have various challenges which revolves around: i) technological barriers which deals with security models, legacy systems and incompatibility of different hardware and standards, ii) organizational barriers this basically deals with stakeholder commitment and lack of readiness iii) strategic barriers (this deals with overambitious goals and poor lack of shared governance) the last iv) policy barriers which basically deals with data ownership and privacy;[16]. "Interoperability is not simply a technical issue concerned with linking up computer networks. It goes beyond this to include the sharing of information between networks and the reorganization of administrative processes to support the seamless delivery of e-Government services."(European Commission, 2004). In addition to achieving interoperability through the standards, architectures have a crucial role in ensuring e-government interoperability success [25].

Data heterogeneity in the public sector is a serious problem and remains to be a key issue as different naming conventions are used to represent similar data labels. The e-government effort in many countries has provided a platform for government entities and their business partners to exchange data through Information Communication Technologies (ICT) and standards such as RosettaNet (B2B data exchange standard), EDIFACT (Electronic Data Interchange for administration, Commerce, and Transport), XML (Extensible Markup Language) and EDI (Electronic Data Interchange) [26].

Electronic Government should be considered as an integral system of political objectives, organizational procedures, information content, ICT technologies, operating within Public Administration so as to contribute to fulfillment of its mission. Electronic Government is not a mere technological infrastructure or strategy but rather a new integrated style of Public Administration organization and operations. Electronic Government addresses all citizens and businesses that Public Administration has a mission to serve, including those handicapped due to physical, social, economic, geographical or cultural factors [27].

Identified as one of the factors affecting the e-government adoption [28], the interoperability was defined as being "the ability of systems, units or forces to provide services to, and accept services from, other systems and to use the services so exchanged to enable them to operate effectively together without altering or degrading the information exchanged. To create efficient public services [29] mention two ways of achieving this, either by the integration of back-offices through centralization of data and services, or by standardizing and clearing, i.e. interoperability. There are several reasons why public administrations cannot fully centralize their tasks and data. These often have to do with legal issues in which central data storage is controversial or forbidden or due to the amount of stakeholders that have their own systems and data, making it difficult to reach agreements on shared services. In these cases interoperability forms a preferable alternative to achieve an efficient back-office, where individual organizations maintain a large part of their internal systems and data. 
By using the interoperability concept to create a seamless exchange of data between government agencies, the information systems in the back-offices of these agencies have to be linked up [29]. Because of its important role in the development of inter-organizational collaboration in e-government and the many definitions that can be found in literature, the interoperability concept will first be clarified.

Initially the interoperability concept was mainly described from a technical perspective and was concerned with the coupling of diverse and disparate IT systems. The Institute of Electrical and Electronic Engineers (IEEE) defined interoperability as "the ability of two or more systems or components to exchange information and to use the information that has been exchanged." (IEEE, 1990). In this context, interoperability mainly refers to ensuring that data can be exchanged between diverse systems that are located in different locations. This includes creating and agreeing on the signals exchanged, such as protocols for data transfer. Furthermore decisions on processing the received data have to be made, by creating and agreeing on standardized data exchange formats such as XML.

However, interoperability in an e-government context goes beyond this technical dimension, by also including the reorganization of different administrative processes, aligning different organizational structures and agreeing on the meaning of what is exchanged. These aspects make the problem more complex and require a broader definition of the interoperability concept. A definition of interoperability with a broader scope comes from the framework of panEurope e-Government services [20].

The second version of this framework (European Commission, 2010) defines interoperability as follows: "...the ability of disparate and diverse organizations to interact towards mutually beneficial and agreed common goals, involving the sharing of information and knowledge between the organizations via the business processes they support, by means of the exchange of data between their respective information and communication technology (ICT) systems".

IS interoperability is therefore an important element for a successful implementation of government services. To improve IS interoperability on the level of implementation the critical factors identified are technical, semantic and organizational interoperability this approaches should be addressed in e-Government programs [31].

\section{METHODOLOGY}

The generic of this study was qualitative and quantitative type of research. This research used descriptive survey to accomplish research objectives. Descriptive survey was suitable as it helped to determine characteristics of subjects involved in e-government heterogeneous information system interoperability. The focus of the study was to understand the critical factors affecting interoperability which will eventually the researcher came up with a framework that could be used to inform and guide interoperability heterogeneous information system process. To realize the study aim, the research had to conform to the types of interoperability which are technical, organizational and semantic interoperability and understand the critical factors that has a bearing on the development of an interoperability model for heterogeneous information system in government. The study used expert opinion to validate the proposed interoperability framework in e-government heterogeneous information system. Expert opinion is a technique that can be used in problem identification, clarifying the issues relevant to a particular topic and in the evaluation of products (Whitfield et al, 2008).The study adopted this approach to validate the research model.

3.1. Location of the Study: The study covered three e-government applications that were being used in county governments in Kenya which were as follow: - IFMIS which is the payment module, the IPPD used for payroll payments and LAIFOMS which is used to collect revenue in the county level. These e-government information systems brought out the aspects of interoperability as the basis of the research. The study was conducted in the two county governments and two huduma centres's whose key role was to implement government information policies and also that's where the above applications were being hosted. The study was also conducted in two counties Kakamega County and Uasin-gishu County because they represent the end-users of the information systems. The respondents comprised of ICT technician, Human Resource officers and Finance officers who were most suitable to provide information of this research due to their strategic role in the national government and county government administration.

3.2. Target Population : Target population was the entire set of units for which the study data was used to make inferences. The target population defines those units for which the findings of the study are meant to generalize (Dempsey, 2003). Staffs that interact with the e-government information system were of two types, expert and nonexperts users. Expert's users referred to the personnel who were responsible for the acquisition or development, implementation, utilization and management of information systems in government, therefore they were ICT personnel. Non-expert users on the other hand were just users of the IS and they had no expertise on its acquisition, development or management; typically finance officers and human resource officers, who did not fall on the expert category. The data collected from these groups provided a good representation of the sample. Interviews were also carried out to experts of government ministries and private sector. 
3.3. Sampling Technique: The study used both stratified and purposive sampling in the study. The population was stratified into three strata namely Finance officers, Human Resource officers and ICT personnel. Kothari (2004) notes that if a population from which a sample is to be drawn does not constitute homogeneous group, stratified sampling technique is generally applied in order to obtain representative sample. Under the stratified sampling, the population is divided into several sub populations that are individually more homogeneous than the total population called strata. After putting the groups into strata, purposive sampling was applied in each stratum to target respondents who were believed to be reliable enough for the study. According to Yin (2013), respondents who are particularly informative enough to respond to research questions were selected to enable effective attainment of research objectives. For the finance officers' strata, this study purposefully selected them as end-users of the selected e-government information systems. This research considered the fact that the selected finance officers had experience in e-government information systems. For the ICT stratum, this study sought to select non-experts randomly and expert's users were chosen purposively.

3.4. Sample Size: Kothari, (2004) notes that if a population from which a sample is to be drawn does not constitute homogeneous group, stratified sampling technique is generally applied in order to obtain representative sample. Under the stratified sampling, the population is divided into several sub populations that are individually more homogeneous than the total population called strata. (Kothari, 2004). Due to the heterogeneity of the respondents in the target population because of their professions, academic training, orientation and exposure, stratified purposive sampling was used. Suppose the disjointed groups from the two targeted institutions are $\mathrm{N}_{1}$ and $\mathrm{N}_{2}$ units respectively. These subgroups, called strata, together compromise the whole population, so that $\mathrm{N}_{1}+\mathrm{N}_{2}=\mathrm{N}$ as illustrated below form the target stratum. The values of targeted institutions forming the strata in table 3.1 .

Table 3.1: Table of Target Population

\begin{tabular}{|l|l|l|l|l|c|}
\hline STAFF CATEGORY & \multicolumn{5}{l|}{ TARGET POPULATION } \\
\hline & $\begin{array}{l}\text { KAKAMEGA } \\
\text { COUNTY } \\
\text { GOVERNMENT }\end{array}$ & $\begin{array}{l}\text { KAKAMEGA } \\
\text { HUDUMA } \\
\text { CENTRE }\end{array}$ & $\begin{array}{l}\text { UASIN-GISHU } \\
\text { COUNTY } \\
\text { GOVERNMENT }\end{array}$ & $\begin{array}{l}\text { UASIN-GISHU } \\
\text { COUNTY } \\
\text { GOVERNMENT }\end{array}$ & TOTAL \\
\hline Finance officers & 19 & 2 & 30 & 4 & 55 \\
\hline ICT officers & 13 & 2 & 13 & 5 & 33 \\
\hline Human resource officers & 3 & 2 & 4 & 3 & 12 \\
\hline
\end{tabular}

In order to get the required information with the least sampling error, the following statistical formula was used to determine the sample size

Equation used for Determining Final Sample Size

$$
\mathrm{n}=\frac{\mathrm{N}}{1+\mathrm{N}(\mathrm{e})^{2}}
$$

Where $\mathrm{n}$ is the sample size, $\mathrm{N}$ is the target population, and e is the level of precision (say 95 per cent confidence level $( \pm 5 \%$ precision). The table 3.1 shows the strata target population as per each ministry/department. The target population in all the four sampled departments is 100 as shown in table 3.1

$$
\frac{\mathrm{ni}}{\mathrm{N}} * \mathrm{n}
$$

where;

ni is the size of the specific stratum,

$\mathrm{N}$ is the target population,

$\mathrm{n}$ is the sample size of all the strata.

\section{DATA ANALYSIS AND PRESENTATION}

4.1 Reliability test

\begin{tabular}{lc}
\hline Variable & Cronbach alpha \\
\hline ICT infrastructure & .941 \\
\hline Data information integration & .820 \\
\hline Standards and policies & .923 \\
\hline Collaboration & .781 \\
\hline E-Gov heterogeneous information system interoperability & .886 \\
\hline
\end{tabular}

Source: (Researcher, 2018) 
The results indicated that all the variables obtained had Cronbach's Alpha greater than 0.7 thereby achieving the recommended 0.7 for internal consistence of data (Mugenda \& Mugenda, 2008). Data validity is the degree to which a test measures that which it is supposed to measure (Porter, 2010). Mugenda and Mugenda (2008) define validity as the degree to which the research results obtained from the analysis of the data represent the phenomenon under study. According to Table 4.2 Kaiser-Meyer-Olkin measure of sampling adequately indicated KMO value of greater than 0.5 meaning thereby that the sample size was good enough to treat the sampling data as normally distributed. KMO value above 0.5 considered to be high enough to consider the data as normally distributed. Bartlett's test sphericity which tested the null hypothesis "item to item correlation matrix based on the responses received from respondents for all the effective variables was an identity matrix". The Bartlett's test was evaluated through chi-square test as shown in Table 4.2 for the entire variables and were all significant at $5 \%$ level of significance, indicating that null hypothesis is rejected.

Table 4.2: Test for validity

\begin{tabular}{|l|c|c|c|c|}
\hline Factors & \multirow{2}{*}{ KMO test } & \multicolumn{3}{|c|}{ Barlett's test of sphericity } \\
\cline { 2 - 5 } & & Chi-Square & df & Sig. \\
\hline ICT infrastructure & .740 & 228.45 & 4 & 0.001 \\
\hline Data information integration & .726 & 320.61 & 4 & 0.002 \\
\hline Standards and policies & .529 & 221.40 & 4 & 0.004 \\
\hline Collaboration & .574 & 374.40 & 4 & 0.000 \\
\hline E-Gov heterogeneous information system interoperability & .641 & 186.60 & 4 & 0.000 \\
\hline
\end{tabular}

Extraction Method: Principal Component Analysis.

Source: (Researcher, 2018)

\subsection{Relationships}

The Pearson product-moment correlation was used to determine if significant relationships existed between different combinations of variables. The variables consisted of the interoperability adoption factors that were most frequently stated by interviewees (see Table 4.3). Correlations where tested by comparing and contrasting different combinations of variables. The four statistical significant correlations identified between the different variable combinations are presented in Table 4.3 .

Table 4.3: Interoperability Adoption Factors Correlation Matrix

\begin{tabular}{llll}
\hline Variable & Connectivity & Infrastructure Security & Accountability \\
\hline Data Security & $\mathrm{r}=0.53 ; \mathrm{p}=0.006$ & & \\
Standards & & & $\mathrm{r}=0.48 ; \mathrm{p}=0.012$ \\
Data Quality & & $\mathrm{r}=-0.53 ; \mathrm{p}=0.005$ & \\
\hline
\end{tabular}

\section{Source: (Researcher, 2018)}

A number of significant relationships where also identified for the following dependant and independent variable combinations:

- $\quad$ 'Data Security' and 'Connectivity' where found to be statistically significantly correlated at the $1 \%$ level $(\mathrm{r}=0.53 ; \mathrm{p}=0.006)$.

- 'Compatibility' and 'Infrastructure Security' where found to be statistically significantly correlated at the $1 \%$ level $(\mathrm{r}=0.53 ; \mathrm{p}=0.005)$.

- 'Accountability' and 'Standards' where found to be statistically significantly correlated at the $5 \%$ level $(\mathrm{r}=0.48 ; \mathrm{p}=0.012)$.

The highest significant level of correlation was found between the variables 'Data Security' and 'Connectivity' and 'Standards' and 'Accountability'. The lowest significant level of correlation was indicated as the variables 'Accountability' and 'Compatibility'. Three notable statistical significant correlations where also found between different interoperability factor variables. The correlations suggest that 'Data Security' and 'Standards' plays a major role in the 'Connectivity' of Information Systems. The correlations identified further suggest that 'Accountability' plays a role in 'Data Quality' and that 'Compatibility' plays a role in the form of 'Infrastructure Security' established. The identified correlations are not necessarily cause-effect correlation relationships. 


\subsection{Summary of Analysis}

From the data analysis results it was established under communication interoperability that the main protocols identified were FTP, HTTP and VSP these protocols were identified as the best protocols for exchanging data between interoperability partners. Data security also was identified as a key element to achieve interoperability by addressing the attributes which are authentication of data, authorization, encryption and hashing. Architectural level information systems were required to be organized in either client-server architectural model. There is also a need for organizations to use newer types of system architectures such as the service oriented architecture and peer-to-peer architecture for data sharing and service delivery. Seven services were also identified that had to be provided by the system architectures identified such as: a) data import/export services, (b) File transfer services, (c) Remote Procedure Calls, (d) Transactional services, (e) Web Services (f)Security Management Services. The interviewees indicated that data exchange between partners should make use of File, XML and object presentation formats. The architectural forms, services, protocols and presentation formats identified by interviewees indicates that a interoperability framework should be developed that conforms to the requirements identified by the experts. For data to be shared amongst different platforms and entities organizations should use a shared communication network such as LAN and WAN.

In summary the e-government heterogeneous information system interoperability framework required will need to provide the services identified by interviewee, comply with policies and standards and accommodate the legacy infrastructure and software. The technical interoperability factors identified also plays a key role in addressing the final framework.

\subsection{Regression analysis and Model}

The ANOVA test is used to determine whether the model is important in predicting the interoperability of egovernment heterogeneous information systems in Kenya. From findings in Table 4.4, the value of R-Square is 0.128. This implies that, $12.8 \%$ of variation of e-Gov heterogeneous information system interoperability was explained by ICT infrastructure, Collaborative, Data and information integration, Standards and policy.

Table 4.4: Model summary

\begin{tabular}{|l|l|l|l|l|l|l|l|}
\hline \multicolumn{9}{|l|}{ Model Summary } \\
\hline \multirow{2}{*}{ Model } & R & R Square & $\begin{array}{l}\text { Adjusted } \\
\text { R Square }\end{array}$ & $\begin{array}{l}\text { Std. Error of the } \\
\text { Estimate }\end{array}$ & \multicolumn{2}{l|}{ lhange Statistics } & \\
\cline { 5 - 8 } & R Square Change & F Change & Sig. F Change \\
\hline 1 & .168 & .128 & .025 & 3.122 & .128 & .527 & .006 \\
\hline
\end{tabular}

Source: (Researcher, 2018)

a. Predictors: (Constant), ICT infrastructure, Collaborative, Data and information integration, Standards and policy

At 0.05 level of significance the ANOVA test indicated that in this model the independent variables namely; ICT infrastructure, Collaborative, Data and information integration, Standards and policy variables were predictors of eGov heterogeneous information system interoperability as indicated by significance value $=0.006$ which is less than 0.05 level of significance $(\mathrm{p}=0.006<0.05)$.

Table 4.5: ANOVA table

\begin{tabular}{|l|l|l|l|l|l|}
\hline Model & Sum of Squares & Df & Mean of Squares & F & Sig \\
\hline Regression & 20.560 & 4 & 5.140 & .527 & $.006^{\mathrm{a}}$ \\
\hline Residual & 711.555 & 73 & 9.747 & & \\
\hline Total & 732.115 & 77 & & & \\
\hline
\end{tabular}

\section{Source: (Researcher, 2018)}

a. Predictors: (Constant), ICT infrastructure, Collaborative, Data and information integration, Standards and policy

b. $\quad$ Dependent Variable: e-Gov heterogeneous information system interoperability

From the findings in Table 4.5 above; at $5 \%$ level of significance, the association of the dependent and independent variables is summarized as follows

$$
Y=\beta_{0}+\beta_{1} X_{1}+\beta_{2} X_{2}+\beta_{3} X_{3}+\beta_{4} X_{4}
$$

Where $Y$ is e-Gov heterogeneous information system interoperability, ${ }_{1}$ is data and information integration, $X_{2}$ is data and information integration, $X_{3}$ standards and policies, and $X_{4}$ is ICT infrastructure Using the regression coefficients in Table 4.6, we have;

$$
Y=9.010+0.106 * X_{1}+0.095 * X_{2}+0.110 * X_{3}+1.025 * X_{4}
$$


From the equation above when data and information integration is increased by one unit, e-Gov heterogeneous information system interoperability will increase by 0.106 , a unit increase in data and information integration will result to 0.095 increase in e-Gov heterogeneous information system interoperability, a unit increase in standards and policies will result to 0.110 increase in e-Gov heterogeneous information system interoperability, a unit increase in ICT infrastructure will result to 1.025 increase in e-Gov heterogeneous information system interoperability.

\begin{tabular}{|c|c|c|c|c|c|}
\hline \multirow[t]{2}{*}{ Model } & \multicolumn{2}{|c|}{ Unstandardized Coefficients } & \multirow{2}{*}{$\begin{array}{l}\text { Standardized } \\
\text { Coefficients } \\
\text { Beta }\end{array}$} & \multirow[t]{2}{*}{$\mathrm{T}$} & \multirow[t]{2}{*}{ Sig. } \\
\hline & $\mathrm{B}$ & Std. Error & & & \\
\hline 1 (Constant) & 9.010 & 6.426 & & 2.514 & .000 \\
\hline $\begin{array}{l}\text { Data and information } \\
\text { integration }\end{array}$ & .106 & .118 & .105 & .901 & .003 \\
\hline Collaborative & .095 & .102 & .108 & .932 & .005 \\
\hline Standards and policy & .110 & .160 & .080 & .687 & .004 \\
\hline ICT infrastructure & 1.025 & .126 & .024 & .202 & .001 \\
\hline
\end{tabular}

\section{Source: (Researcher, 2018)}

a. Dependent Variable: e-Gov heterogeneous information system interoperability

\subsection{Analyzing the Moderating Factors}

It was necessary to examine whether e-government commitment by government bodies, Top management support and ICT literacy skills are moderating variables partially or wholly related to the independent variables influencing success of heterogeneous I.S interoperability.

Table 4.7: Moderating factors of interoperability

\begin{tabular}{lllll}
\hline Control Variables & $\begin{array}{l}\text { ICT } \\
\text { infrastructure }\end{array}$ & Collaboration & $\begin{array}{l}\text { Data and } \\
\text { Information } \\
\text { integration }\end{array}$ & $\begin{array}{l}\text { Standards } \\
\text { and } \\
\text { policies }\end{array}$ \\
\hline $\begin{array}{l}\text { Commitment by } \\
\text { government bodies }\end{array}$ & 0.182 & 0.030 & 0.591 & 0.291 \\
$\begin{array}{l}\text { Top Management } \\
\text { Support }\end{array}$ & 1.000 & 0.192 & 0.182 & 0.024 \\
ICT literacy levels & 0.024 & 0.131 & 0.192 & 0.223 \\
\hline
\end{tabular}

\section{Source: (Researcher, 2018)}

Correlation is significant at the 0.05 level (2-tailered)

The partial spearman correlations procedure computes partial correlation coefficients that describe the relationship between two variables while controlling for the effects of one or more additional variables. In this study we sought to establish whether commitment of government bodies, top management support and ICT literacy levels affect the relationship between the independent and dependent variables.

Table 5.4 shows the partial correlation controlling commitment by government bodies, top management support and ICT literacy levels which indicate that their presence reduces the impact of ICT infrastructure, collaboration, data and information integration and standard and policies on achieving interoperability in heterogeneous information systems. One interpretation of this finding is that the observed positive "relationship" between ICT infrastructure, collaboration, data and information integration and standard and policies is due to underlying relationships between each of the variables and the commitment of government bodies, top management support and ICT literacy levels. ICT infrastructure, collaboration, standard and policies and data and information integration increases success rate to achieve interoperability of heterogeneous information systems because of commitment by government bodies, Top management support and ICT literacy levels. Thus for interoperability to be achieved amongst heterogeneous information systems the three moderating factors should be put into consideration. In conclusion the conceptual framework that was formulated from the data analysis findings. The framework indicates the interoperability domains and relationships between them. The framework further shows that the domains will individually as well as collectively influence the establishing of interoperability amongst heterogeneous e-government information systems..

\subsection{Discussion of the results}

In summary, the study showed that the adoption of interoperability will be influenced by a large number of factors within different domains of which a small number of factors were in correlation relationships with one another. The interoperability factors identified have to be taken into account when examining the risk of establishing interoperability or when implementing an interoperability solution. 
From the data analyses results, 24 distinct interoperability adoption factors were identified that will influence the establishing of interoperability within the public service. From the 24 interoperability factors identified, the seven most identified interoperability adoption factors are the following:

a) Standard: For interoperability to be achieved there should be a common standard for there to be efficient and effective communications amongst the government information system.

b) Data Security: Interoperability solutions should ensure protection of data within hosting environments and data in-use within applications.

c) Infrastructure Security: Infrastructure should protect data in motion and at rest, ensuring data confidentially, integrity and availability (i.e., CIA).

d) Data Quality: Data to be shared among Information Systems should be accurate, precise, complete, usable and consistent. Connectivity: Before data exchange can take place between Information systems, physical interoperability (e.g., LAN and WAN) should be established between systems.

e) Performance: Interoperability solutions should provide acceptable throughput and response times for all data requests made between systems.

f) Accountability: A person or organization should be made and held responsible for the upkeep and protection of data provided to other users.

g) Compatibility: Hardware and software should be designed or made to be compliant with each other.

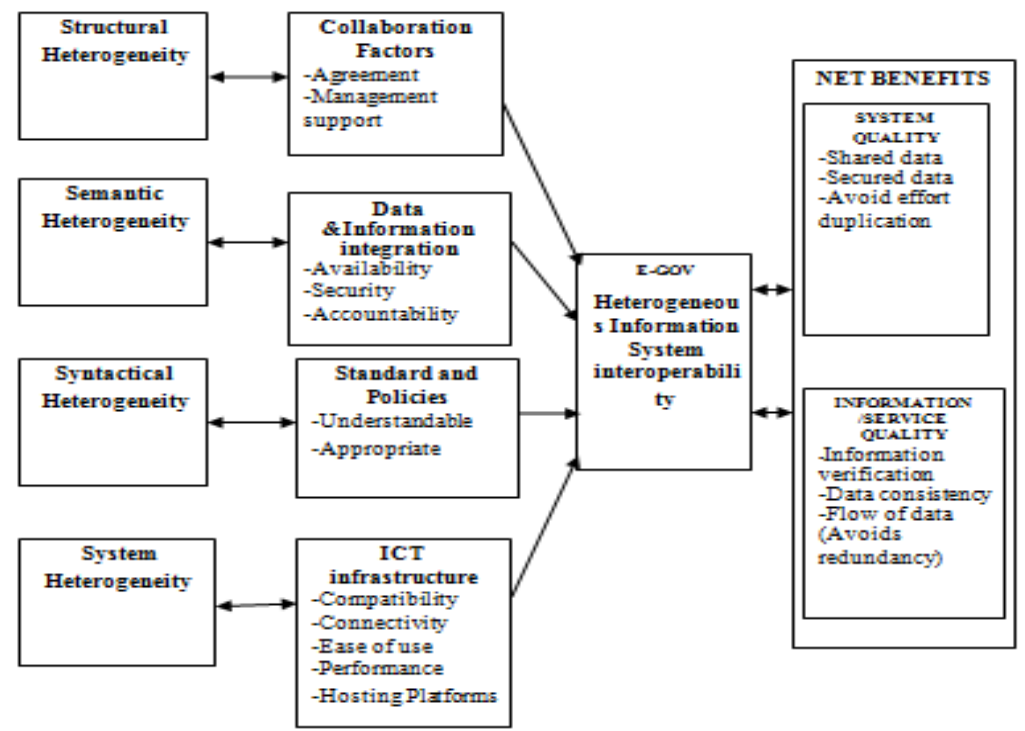

Figure 5.5: E-Government Heterogeneous Interoperability Framework

Source: (Researcher, 2018)

\section{CONCLUSION AND RECOMMENDATION}

The researcher wished to test relationships between these independent variables and the dependent variables while moderating using commitment of government bodies, Top Management support and ICT literacy level. Spearman's rho was used to test the relationship and was proved to be true that, there exist relationship between the determinants of the interoperability and the rate of interoperability. Literature was also reviewed on the existing interoperability framework in heterogeneous information systems. Other existing frameworks were reviewed to enhance the study which included; Australian Interoperability Framework, New Zealand e-Government Interoperability Framework, European Interoperability Framework, European Interoperability Framework. Interoperability assessment models were also reviewed to assist in evaluating the model. These included LISI, CMMI, OIMM GIMM and ISIMM. The comparison showed that the existing interoperability maturity models (LISI, OIMM, CMMI, GIMM, and ISIMM) were partial models only dealing with some aspects of the interoperability domain (i.e. interoperability dimensions). It was necessary to structure them into a single complete interoperability maturity model to avoid redundancy and ensure consistency.. Based on this analysis, the reviewed maturity models are complementary rather than contradictory. It is therefore possible to structure them into one single maturity framework in a harmonized way to look for completeness and avoid redundancy. The literature study revealed that researchers across the globe are studying the effects of eGovernment to enhance interoperability. As a result of poor integration planning and inadequate standards, cost reduction, which is deemed the definite benefit, is not achieved. Barriers such as processes, organizational and technological that hinders smooth implementation of the e-Government calls for more drastic measures such as 
organizational reengineering. Knowledge obtained from this review of literature helped in the development of interoperability model for e-government heterogeneous information system which was the end result of this study.

\subsection{Recommendations}

For governments to deploy fully interoperable systems, Governments should embrace use of e-government architecture as a means of addressing weak interoperability in government. For successful deployment of interoperable systems details and parameters of each and every layer of the architecture should be taken into account. Developed systems must be validated to ensure user satisfaction. Security must be factored during system development and deployment. Technology should not be used as a means of e-governance but rather than an enabler of e-governance. Information that spans multiple agencies is very essential to successful process redesign in government for interoperable system development. Based on the findings of this study, the Government stands to improve services by implementing interoperability of heterogeneous information system. The specific issues that needs to be addressed in this process includes but not limited to:-

(i) The need to addressing interoperability in national ICT master plans and in policy directives is of paramount importance in order for the Government to offer services more efficiently.

(ii) Need for addressing data heterogeneity is important in order to achieve the specific interoperability

(iii) There is an apparent need for addressing stakeholder involvement, bureaucracy, data ownership and business process reengineering in a coherent manner while addressing data interoperability. Further research is necessary to investigate how the three are inter-related.

(iv) Security is a very critical ingredient of interoperability. Proper change management and awareness creation is important for the whole exercise to succeed.

\subsection{Future Work}

\section{Develop an interoperability heterogeneous information system tool}

Future study to explore on some other form of interoperability using Application Programming Interface (API).

II. Develop an organizational interoperability among collaborating government and its stakeholders. The technical interoperability study performed can be extended in the future to the domain of organizational interoperability. The organizational interoperability study can for example look at interoperability of business goals, business processes and data architectures within the Public Service.

III. Challenges of data integration and interoperability in big data

Overall, data integration and data interoperability influence the organization's performance. The data integration and data interoperability are complex challenges for the organizations deploying big data architectures due to the heterogeneous nature of data used by them.

IV. Appropriate metrics should be defined and used at regular interval to measure the success of interoperability.

\section{REFERENCES}

[1]. A. \& S. Ahmed, "Acceptance of e-Government Services in Sudan:an Empirical Investigation," in International Conference in Cloud Computing (ICCC), 2015, pp. 1-4.

[2]. Pardo \& Tayi, "Interorganizational information integration: a key enabler for digital government," Gov. Inf. Q., vol. 24, no. 4, pp. 691-715, 2007.

[3]. Pardo \& Burke, "Improving Government Interoperability: A capability framework for government managers.," 2008.

[4]. Lallana, "e-Government Interoperability. Guide, United Nations Development Programme," vol. ISBN: 978-, 2007.

[5]. A. \& A. Al Hujran, "Factors influencing citizen adoption of e-government in developing countries: The case of Jordan," Int. J. Technol. Hum. Interact., vol. 9, no. 2, pp. 1-19, 2013.

[6]. Ornager \& Verma, "e-Government Tool-Kit for Developing Countries," 2005.

[7]. Al-Shboul et al, "Challenges and Factors Affecting the Implementation of e-Government in Jordan," J. Softw. Eng. Appl., vol. 7, no. 13, pp. 11-12, 2014

[8]. Wauters et al, "Study on cloud and service oriented architectures for e-government for Deloitte," 2012.

[9]. E-Government, "E-Governmnet Strategy: The strategic framework, Administrative Structure, Training Requirements and Standardization Framework," Nairobi,Kenya: Republic of Kenya, 2004.

[10]. et al Janssen, “E-government Interoperability,” J. Theor. Appl. Electron., vol. 6, pp. 23-40, 2011.

[11]. Cava \& Guijarro, "Interoperability issues of shared infrastructures for e-government. Paper presented at the EGOV," Prague, Czech Republic, 2003.

[12]. Hjort-Madsen, "Enterprise architecture implementation and management: A case study on interoperability," in Paper presented at the 39th Hawaii International Conference on System Sciences (HICSS-39), 2006.

[13]. Ebbers \& van Dijk, "Resistance and support to electronic government,building a model of innovation," Gov. Inf. Q., vol. 24, pp. 554-575, 2007.

[14]. Novakouski and Lewis, "Interoperability in the e-Government Context," Carnegie Mellon Univ. Eng. Inst., 2012.

[15]. Gottschalk \& Solli-Sæther, "Stages of e-government interoperability. Electronic Government," An Int. J., vol. 5, no. 3, pp. 310-320, 2008.

[16]. Lam, "Barriers to e-government integration," J. Enterp. Inf. Manag., vol. 18, pp. 511-530, 2005.

[17]. European Union, "Open Government Directive.Memorandum for the Heads of Executive Departments and Agencies," 2009. [Online]. Available: http://www.whitehouse.gov/omb/assets/memoranda_2010/m10-06.pdf. [Accessed: 26-Apr-2017].

[18]. Hellman, "Organizational barriers to interoperability:In eChallenges," 2010, pp. 1-9.

[19]. et al Lee, "E-government Data Interoperability Framework in Hong Kong.In Interoperability for Enterprise Software and Applications China, 2009," in IESA'09. International Conference, 2009, pp. 239-244.

[20]. European Commission, "European Commission. European Interoperability Framework for Pan-European eGovernment Services.Official Publications of the European Communities.," 2004. 


\title{
International Journal of Advanced Research in Computer and Communication Engineering
}

\author{
Vol. 7, Issue 10, October 2018
}

[21]. Tushman, "Competing by Design. The Power of Organizational Architecture," Newyork, 1997.

[22]. Alonso et al, "'Developing an Enterprise Collaboration Maturity Model: Research Challenges and Future Directions.',", 2009.

[23]. Cresswell \& Pardo, "Sharing Justice Information: A Capability Assessment Toolkit. Albany: Center for Technology in Government," Research Foundation of State University of New York, 2005. [Online]. Available: Research Foundation of State University of New York.

[24]. Deller, "Open source software movement in French Central and local government: a retrospective and prospective explatory study," Int. J. Electron. Democr., vol. 1, no. 1, pp. 1-13, 2008.

[25]. Saekow \& Boonmee, "“Towards a Practical Approach for Electronic Government Interoperability Framework (e-GIF),"” in Proceedings of the 42nd Hawaii International Conference on System Sciences, 2009.

[26]. Muthaiyah and Kerschberg, “"Achieving interoperability in egovernment services with two modes of semantic bridging: SRS and SWRL," J. Theor. Appl. Electron. Commer. Res. ISSN 0718-1876 Electron. Version, vol. 3, no. 3, pp. 52-63, 2008.

[27]. Dimitris;Mentzas and Panagiotis, “" Planning and Implementing e- Government Service Delivery: Achievements and Learnings from On-line Taxation in Greece"," in Presented at the Workshop on e-Government in the context of the 8th Panhellenic Conference on Informatics, 2001.

[28]. Ebrahim \& Irani, "E-government Adoption: Architecture and Barriers,” Bus. Process Manag. J., vol. 11, no. 5, pp. 589-611, 2005.

[29]. Kubicek \& Cimander, "Three dimensions of organizational interoperability: Insights from recent studies for improving interoperability frameworks," Eur. J. ePractice, vol. 6, pp. 1-12, 2009.

[30]. IEEE, "IEEE standard computer dictionary: a compilation of IEEE standard computer glossaries,” New York, NY, 1990.

[31]. Tambouris et al, "The role of interoperability in eGovernment applications: An investigation of obstacles and implementation decisions," in In Digital Information Management, 2008. ICDIM 2008. Third International Conference on, 2008, pp. 381-386.

\section{BIOGRAPHIES}

Ronoh Hillan received BSc in Computer Science of University of Eldoret in 2013. He is currently working as a Instructor at the School of Computing and Informatics, Masinde Muliro University of Science and Technology, Kenya. His current research interests include; security, and Information systems.

Kelvin Omieno a Lecturer at the Department of Computer Science, School of Computing and Informatics, Masinde Muliro University of Science and Technology, Kenya. He holds a PhD in Information Systems of Jaramogi University of Science and Technology, Kenya. His research interests are in performance evaluation, System optimization, security and parallel and distributed systems

Stephen Mutua a Senior lecturer at the Department of Information Technology, School of Computing and Informatics, Meru University of Science and Technology, Kenya. He holds a PhD (System Analysis \& Integration) of University of Shangai for Science \& Technology (USST), China. His research interests are in data mining and machine learning. 